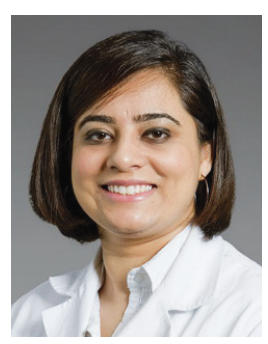

\title{
ROLE OF CARDIAC MRI IN THE ASSESSMENT OF NONISCHEMIC CARDIOMYOPATHIES
}

\author{
Mahwash Kassi, M.D.; Faisal Nabi, M.D.
}

Houston Methodist DeBakey Heart \& Vascular Center, Houston Methodist Hospital, Houston, Texas

M. Kassi, M.D.

\section{Abstract}

In this review, we will highlight the role of late gadolinium enhancement, along with other strengths available by cardiac MRI, in determining the underlying etiology of various nonischemic cardiomyopathies. Furthermore, we will also emphasize how late gadolinium enhancement may serve as a novel risk stratification tool to further impact patient care.

\section{Introduction}

Nonischemic cardiomyopathies are generally defined as diseases of the myocardium associated with mechanical dysfunction and either inappropriate dilation or hypertrophy in the absence of an underlying etiology. ${ }^{1}$ They are generally divided into those that are predominantly confined to the myocardium (primary) or those that involve the myocardium as part of a systemic disorder (secondary). Patients may be asymptomatic but frequently present with advanced stages of disease associated with heart failure and arrhythmic events. Management and prognosis frequently depends on the etiology of the cardiomyopathy involved. The first-line imaging test for assessing cardiomyopathies is echocardiography. It is readily available, rapidly performed, and provides accurate hemodynamic assessment in addition to identifying possible etiologies noninvasively. Recently, cardiac magnetic resonance imaging (CMR) has proven to be a powerful and effective adjunct to echocardiography in the evaluation of cardiomyopathies.

In a single 45- to 60-minute CMR study, a thorough assessment of a patient's cardiomyopathy can be performed. With its high spatial and temporal resolution, detailed three-dimensional (3D) images of cardiac and thoracic anatomy can be obtained free of limitations from body habitus or standard imaging planes. The gold standard for quantification, accurate and reproducible assessment of biventricular cardiac volumes and function can have profound implications regarding medical management. Concomitant valvular heart disease can be quantified with phase contrast techniques, and ischemia testing can be performed with first-pass perfusion during vasodilator stress. Finally, a feature most unique to CMR is the opportunity for accurate tissue characterization. Noncontrast T1- and T2-weighted sequences reliably assess edema and fat infiltration, and $\mathrm{T} 2 *$ sequences identify myocardial overload. The administration of gadolinium contrast, on the other hand, helps in the assessment of thrombus, and late gadolinium enhancement (LGE) techniques accurately image areas of myocardial fibrosis or infiltration.

In this review, we will highlight CMR imaging characteristics of the more common nonischemic cardiomyopathies and how the extent and pattern of LGE can not only help identify the underlying pathological process but, importantly, also may now provide novel insight into predicting prognosis (Table 1).

\section{Dilated Cardiomyopathies}

Dilated cardiomyopathy (DCM) is defined as systolic dysfunction, either the left ventricle alone or biventricular, with concomitant dilation. Although the etiology is not known in many cases, it is broadly defined as either ischemic or nonischemic (e.g., genetic, myocarditis, cardiac toxins). CMR aids in the evaluation of cardiomyopathies by readily providing accurate and reproducible measurements of biventricular volumes and ejection fractions without geometric assumptions, evaluating valvular heart disease and detecting thrombus. The addition of LGE can detect patterns of fibrosis that can help differentiate between ischemic versus nonischemic etiologies. With coronary artery disease (CAD), LGE is noted to spread from the subendocardium to epicardium and also follow a typical coronary artery distribution (Figure 1A). In a study comparing DCM patients with and without significant coronary disease by angiography, all CAD patients demonstrated subendocardial scarring. ${ }^{2}$ In contrast, in those with non-ischemic disease, there is absent LGE (59\%) or there is endocardial sparing with replacement fibrosis LGE patterns noted to be mid-wall (28\%), epicardial, or diffusely in a noncoronary artery distribution (Figure 1B). Effectively detecting the presence of significant CAD is important as it identifies both a potentially reversible cause for the patient's cardiomyopathy and also a higher-risk patient cohort. ${ }^{3}$

Mid-wall LGE determined by CMR in nonischemic DCM has been shown to have prognostic value. In a prospective longitudinal study of 472 patients with nonischemic DCM, the presence and extent of mid-wall fibrosis was associated with significantly worse all-cause mortality (absolute risk difference, 16.2\% [95\% CI, 8.2\%-24.2\%]; P <.001) during a median follow-up of 5.3 years independent of age, New York Heart Association (NYHA) functional class, and left ventricular ejection fraction (LVEF). ${ }^{4}$ In addition, mid-wall fibrosis was also independently associated with the prespecified secondary endpoint of sudden cardiac death (SCD) or aborted SCD. This study further demonstrated how the addition of fibrosis to LVEF significantly improved risk reclassification for all-cause mortality and the SCD composite, suggesting a new paradigm with which to guide implantable cardioverter-defibrillator (ICD) implantation. Other smaller studies with broad composite endpoints have also similarly shown that the presence and extent of mid-wall fibrosis predicts worse outcomes. ${ }^{5-7}$ 
Table Summarizing CMR Features of Various Nonischemic Cardiomyopathies

\begin{tabular}{|c|c|c|c|}
\hline Type & Cine Characteristics & $\begin{array}{l}\text { Late Gadolinium } \\
\text { Enhancement (LGE) Patterns }\end{array}$ & LGE and Prognosis \\
\hline $\begin{array}{l}\text { Dilated } \\
\text { Cardiomyopathy }\end{array}$ & $\begin{array}{l}\text { Systolic dysfunction (left } \\
\text { ventricle alone or biventricular) } \\
\text { with concomitant dilation, } \\
\text { valvular lesions, thrombus }\end{array}$ & $\begin{array}{l}\text { - Ischemic heart disease: } \\
\text { subendocardial scarring } \\
\text { - Nonischemic heart diease: } \\
\text { absent LGE or patterns of } \\
\text { fibrosis noted to be midwall, } \\
\text { epicardial, or diffuse in a } \\
\text { noncoronary distribution }\end{array}$ & $\begin{array}{l}\text { Midwall LGE associated with } \\
\text { all-cause mortality, sudden } \\
\text { cardiac death (SCD), or } \\
\text { aborted SCD }\end{array}$ \\
\hline $\begin{array}{l}\text { Hypertrophic } \\
\text { Cardiomyopathy }\end{array}$ & $\begin{array}{l}\text { Abnormal LV hypertrophy } \\
\text { (asymmetrical septal, apical, } \\
\text { localized, or concentric), } \\
\text { systolic anterior motion of } \\
\text { the anterior mitral leaflet } \\
\text { with dynamic outflow } \\
\text { tract obstruction, mitral } \\
\text { regurgitation, apical } \\
\text { aneurysms, myocardial } \\
\text { clefts, and papillary muscle } \\
\text { abnormalities }\end{array}$ & $\begin{array}{l}\text { Patchy, midmyocardial LGE } \\
\text { generally occurring in areas of } \\
\text { hypertrophy and at the junc- } \\
\text { tion of the interventricular } \\
\text { septum and the right ventricu- } \\
\text { lar free wall }\end{array}$ & $\begin{array}{l}\text { All-cause mortality, cardiac } \\
\text { mortality, unplanned } \\
\text { heart failure admissions, } \\
\text { deterioration to New York } \\
\text { Heart Association functional } \\
\text { class III or IV, or heart failure- } \\
\text { related death, ventricular } \\
\text { arrhythmias, and SCD }\end{array}$ \\
\hline $\begin{array}{l}\text { Infiltrative Diseases: } \\
\qquad \text { Amyloidosis }\end{array}$ & $\begin{array}{l}\text { Homogenously thickened } \\
\text { myocardium, interatrial septum } \\
\text { and valve leaflets, and the } \\
\text { presence of pleural and } \\
\text { pericardial effusions }\end{array}$ & $\begin{array}{l}\text { Widespread subendocardial } \\
\text { hyperenhancement often } \\
\text { including the interatrial septum } \\
\text { and right ventricle }\end{array}$ & $\begin{array}{l}\text { Worsening long-term survival, } \\
\text { greater abnormalities in } \\
\text { NYHA functional class, ECG } \\
\text { voltage, left ventricular mass } \\
\text { index, right ventricular wall } \\
\text { thickness, troponin-T, and } \\
\text { B-type natriuretic peptide } \\
\text { levels. }\end{array}$ \\
\hline Sarcoidosis & $\begin{array}{l}\text { Localized areas of wall thinning } \\
\text { and regional wall motion } \\
\text { abnormalities with high signal } \\
\text { intensity on T2 weighted } \\
\text { images }\end{array}$ & $\begin{array}{l}\text { Patchy, midwall, subepicardial, } \\
\text { or even subendocardial with } \\
\text { a predilection to involve the } \\
\text { basal and midseptal segments. } \\
\text { LGE of the RV free wall may } \\
\text { also be a frequent finding }\end{array}$ & $\begin{array}{l}\text { Higher rates for death, } \\
\text { defibrillator shock, } \\
\text { pacemaker, diastolic } \\
\text { dysfunction, decreased right } \\
\text { ventricular ejection fraction, } \\
\text { and evidence of nonsustained } \\
\text { ventricular tachycardias }\end{array}$ \\
\hline Iron Overload & $\begin{array}{l}\text { Findings of dilated } \\
\text { cardiomyopathy with reduced } \\
\text { myocardial T2* values }\end{array}$ & Uncommon & Unknown \\
\hline $\begin{array}{l}\text { ARVD (Arrythmogenic } \\
\text { Right Ventricular } \\
\text { Dysplasia) }\end{array}$ & $\begin{array}{l}\text { Focal thinning, segmental } \\
\text { aneurysms, both regional } \\
\text { and global RV dilation, and } \\
\text { depressed function }\end{array}$ & $\begin{array}{l}\text { RV and/or LV LGE indicates } \\
\text { intramyocardial fibro-fatty } \\
\text { replacement }\end{array}$ & $\begin{array}{l}\text { Induction of ventricular } \\
\text { tachycardia during } \\
\text { electrophysiologic testing }\end{array}$ \\
\hline $\begin{array}{l}\text { Left Ventricular } \\
\text { Noncompaction (LVNC) }\end{array}$ & $\begin{array}{l}\text { Extensive trabeculations and } \\
\text { intratrabecular recesses, } \\
\text { absence of well-formed } \\
\text { papillary muscles }\end{array}$ & Various patterns? & Related to worse EF? \\
\hline
\end{tabular}

Table 1. Cardiac magnetic resonance features of nonischemic cardiomyopathies. 


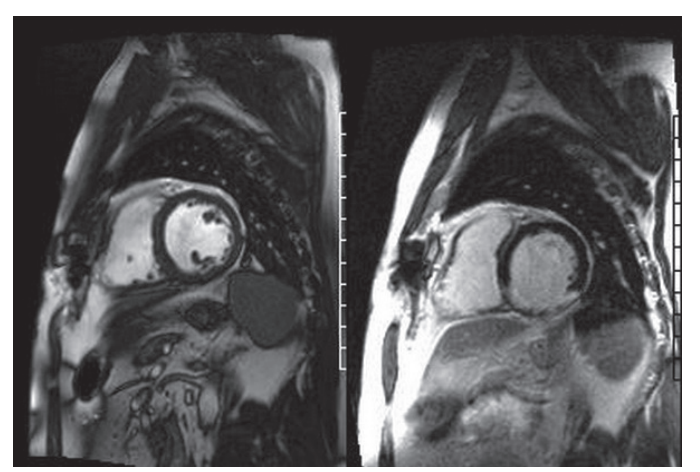

Figure 1A. Ischemic cardiomyopathy. Note large, near transmural infarct extending from the subendocardium involving the midinferoseptum and inferior wall, and posteromedial papillary muscle. Total scar burden was $18 \%$ of the left ventricle (LV). LV ejection fraction was mildly reduced (44\%) with akinesis of the infarcted segments.

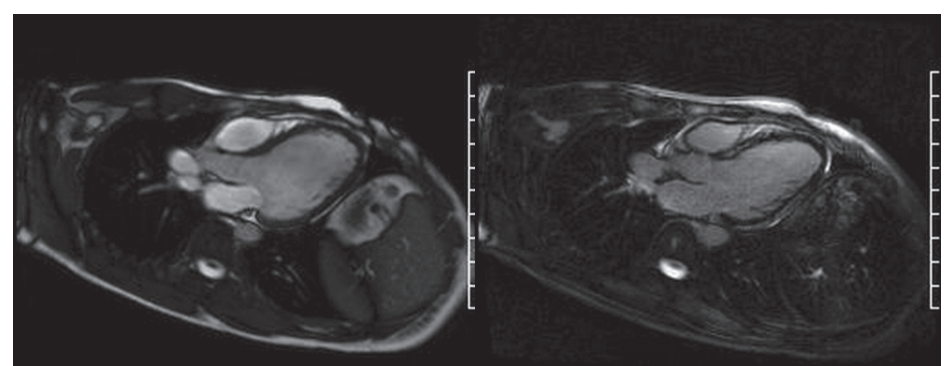

Figure 1B. Nonischemic cardiomyopathy with scar. Left ventricle (LV) is moderately dilated with mild globally depressed LV systolic function and normal right ventricular (RV) systolic function (LV ejection fraction $50 \%$; RV ejection fraction 53\%). Patchy midwall myocardial scarring is evident in the anteroseptum with late gadolinium enhancement.

\section{Hypertrophic Cardiomyopathy}

Hypertrophic cardiomyopathy (HCM) is the most frequent genetic cardiac disease. Affected individuals demonstrate myocyte hypertrophy, disarray, and fibrosis presenting clinically as sudden death, heart failure, or significant morbidity at any age. With excellent spatial resolution and border definition, CMR provides complete visualization of the LV chamber, allowing precise localization of the distribution of hypertrophy and measurement of wall thickness and cardiac mass (Figure 2). Distribution and extent of LV hypertrophy is diverse (asymmetrical septal, apical, localized, or concentric hypertrophy) with most cases, however, demonstrating hypertrophy by CMR of the basal anterior LV free wall and the contiguous anterior ventricular septum. ${ }^{8}$ Furthermore, although HCM may be focal (1-2 LV segments), the vast majority of cases have three or more LV segments involved with at least $15 \mathrm{~mm}$ wall thickness. ${ }^{8} \mathrm{CMR}$ is also superior to echocardiography in the detection of apical and focal basal anteroseptal variants and in recognizing noncontiguous areas of hypetrophy. ${ }^{9} \mathrm{CMR}$ cine imaging provides assessment of additional morphological information including systolic anterior motion of the anterior mitral leaflet with dynamic outflow tract obstruction, mitral regurgitation, apical aneurysms, myocardial clefts, and papillary muscle abnormalities. In addition, stress perfusion imaging can identify areas of microvascular dysfunction or mismatch between LV mass and coronary flow.

In addition to the detection of hypertrophy, late gadolinium enhancement (LGE) plays a further important role in diagnosing and risk stratifying HCM patients. Myocardial fibrosis is present in up to $80 \%$ of patients with HCM, with a characteristic pattern

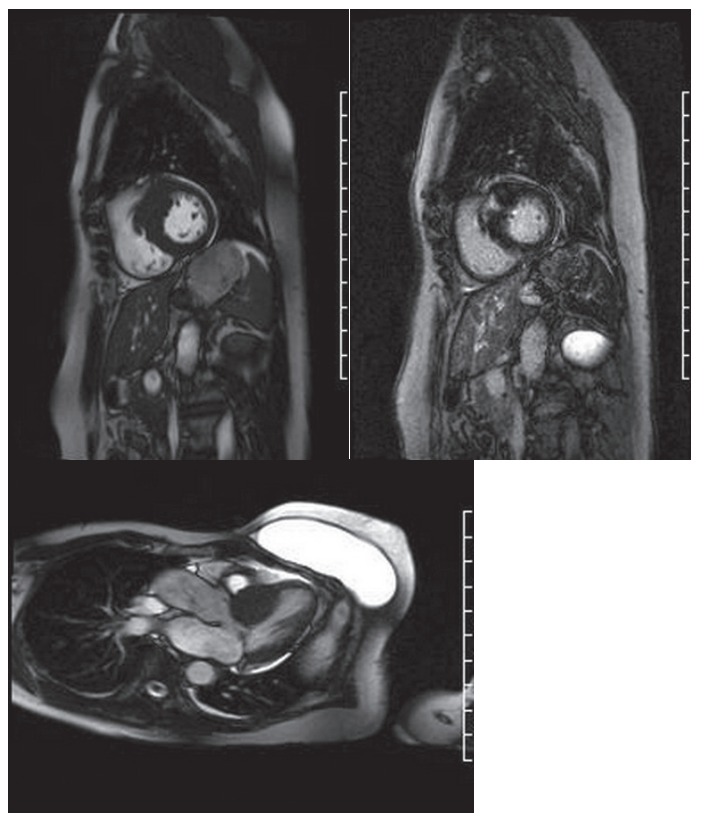

Figure 2. Obstructive hypertrophic cardiomyopathy. Severe asymmetric left ventricular hypertrophy (septum $2.6 \mathrm{~cm}$, lateral wall $0.7 \mathrm{~cm}$ ) with patchy, non-coronary artery disease scarring at the hypertrophied areas and right ventricular insertion sites. Cine steady-state free precession imaging demonstrated systolic anterior motion and dynamic left ventricular outflow tract obstruction with posteriorly directed mitral insufficiency.

of LGE (patchy, mid-myocardial) generally occurring in areas of hypertrophy and at the junction of the interventricular septum and the right ventricular free wall. ${ }^{10}$ In addition, the extent of scarring has been shown to correlate positively with regional hypertrophy and inversely with regional contraction. The presence and extent of LGE has further been shown to have prognostic value in risk stratifying HCM patients. In 243 consecutive patients with HCM, the presence of scar was an independent predictor of death, with an odds ratio of 5.47 for all-cause mortality and of 8.01 for cardiac mortality. ${ }^{11}$ Similarly, the risk of unplanned heart failure admissions, deterioration to NYHA functional class III or IV, or heart failure-related death has been shown to be greater in those with fibrosis (HR: $2.5, \mathrm{P}=.021){ }^{12}$ Although currently not considered an independent risk factor for SCD, LGE extent appears related to ventricular arrhythmias and SCD. In another $424 \mathrm{HCM}$ patients, LGE-positive patients were more likely to have episodes of nonsustained ventricular tachycardia, more episodes of nonsustained ventricular tachycardia per patient, and a higher frequency of ventricular extrasystoles per 24 hours, with all cases of SCD and appropriate ICD discharges occurring in LGE-positive patients. ${ }^{13}$ Recently, a meta-analysis of four studies evaluating 1,063 HCM patients over an average follow-up of 3.1 years demonstrated significant relationships between LGE and cardiovascular mortality, heart failure death, and all-cause mortality and a trend toward significance for LGE and SCD/aborted SCD. ${ }^{14}$

\section{Infiltrative Cardiomyopathies}

The presence of infiltrative cardiomyopathies (amyloidosis, hemochromatosis, sarcoidosis) portends a significantly poorer survival compared to patients with idiopathic cardiomyopathies. ${ }^{15}$ Although echocardiography is very useful in their evaluation, it lacks the ability for reliable myocardial tissue characterization. With several infiltrative cardiomyopathies having characteristic features by $\mathrm{CMR}$, this technique can play a significant role in the 
correct noninvasive diagnosis of different infiltrative disorders, thus guiding treatment, assessing its outcome, and predicting prognosis

Cardiac amyloidosis results from diffuse deposition of amyloid fibrils in the interstitial space. This deposition can virtually affect any part of heart, and cardiac involvement in itself portends poor prognosis. CMR features of cardiac amyloidosis also seen by echo include a homogenously thickened myocardium, interatrial septum and valve leaflets, and the presence of pleural and pericardial effusions. However, on scar imaging, a distinctive pattern of LGE is frequently seen with widespread hyperenhancement of the subendocardium or a global transmural pattern often including the interatrial septum and right ventricle (Figure $3 \mathrm{~A}) .{ }^{16}$ This scar pattern has been shown to have a high diagnostic accuracy for detecting cardiac amyloid when compared to endomyocardial biopsy and has also been shown to be the single best noninvasive imaging parameter for cardiac amyloid. ${ }^{17,18}$ Other less common patterns include mid-wall and subepicardial LGE. Fast washout kinetics of gadolinium into the expanded extracellular space results in suboptimal myocardial nulling on $\mathrm{T} 1$ inversion time scout images, which may also help with diagnosis (Figure 3B). Furthermore, LGE has also been shown to have prognostic value in cardiac amyloidosis. Global LGE pattern is associated with greater abnormalities in NYHA functional class, ECG voltage, left ventricular mass index, right ventricular wall thickness, troponin-T, and B-type natriuretic peptide levels. ${ }^{19}$ The presence of LGE has also been shown to be associated with worsening longterm survival. ${ }^{20-22}$

Sarcoidosis involves the myocardium in $20 \%$ to $30 \%$ of cases. Manifestations of cardiac sarcoidosis include conduction abnormalities, arrhythmias, heart failure, or sudden death. With current treatment options, early diagnosis is beneficial as morbidities can be avoided. CMR cine findings may include localized areas of wall thinning and regional wall motion abnormalities secondary to underlying inflammation. These areas of myocardial inflammation may be seen on T2 weighted images as high-signal intensity. LGE is further beneficial as it identifies areas of myocardial damage and may help guide the site for endomyocardial biopsy. A variety of nonspecific LGE patterns, including patchy, midwall, subepicardial, or even subendocardial, have been described in cardiac sarcoid with a predilection to involve the basal and mid-septal segments. ${ }^{23}$ LGE of the RV free wall may also be a frequent finding. In patients with sarcoidosis, the application of LGE has shown to be more than twice as sensitive in detecting cardiac involvement than current consensus criteria (modified Japanese Ministry of Health), and the occurrence of LGE portends a nine-fold higher rate for adverse events (death, defibrillator shock, or pacemaker). ${ }^{24}$ The presence of LGE is also associated with more diastolic dysfunction, decreased right ventricular ejection fraction, and evidence of nonsustained ventricular tachycardias. ${ }^{25}$ Recently, it was shown that patients with LVEF of $35 \%$ or lower had more transmural and subepicardial lesions and significantly more transmural lesions compared to patients with $\mathrm{LVEF}>35 \%$, and that the number of affected segments of LGE positively correlated with the duration of sarcoidosis. ${ }^{26}$

A major cause of death in patients dependent on blood transfusions is iron overload cardiomyopathy. CMR has made possible accurate detection of both liver and myocardial siderosis using the T2* imaging technique (Figure 4). ${ }^{27}$ The presence of iron deposition in myocardium results in local magnetic field

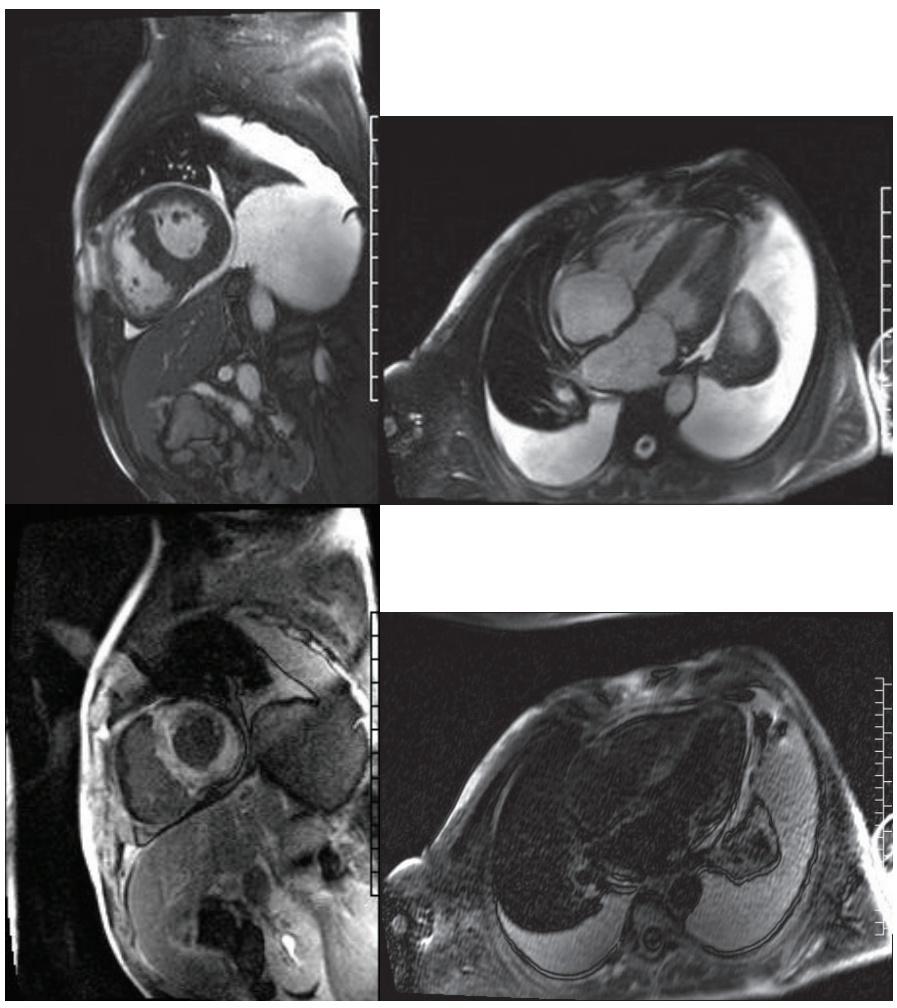

Figure 3A. Cardiac amyloidosis. Cine steady-state free precession images demonstrated biatrial enlargement, moderate concentric LVH, small pleura effusion, large bilateral pleural effusions and moderate global left ventricle (LV) and right ventricle (RV) systolic dysfunction (LV ejection fraction $33 \%$, RV ejection fraction 27\%). Late gadolinium enhancement images demonstrated diffuse subendocardial involvement of the LV and left atrium with sparing of the RV.

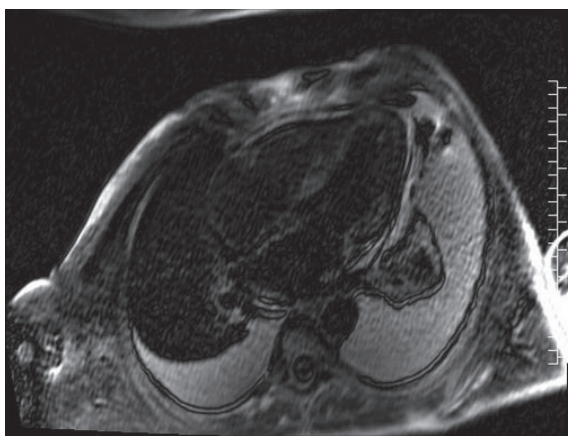

Figure 3B. Cardiac amyloidosis. T1 scout images demonstrate nulling of the blood pool (dark) before the myocardium (bright). This is a characteristic finding, with the myocardium having shorter T1 values than blood due to extensive extracellular space expansion and rapid myocardial gadolinium uptake.

inhomogeneities, which in turn results in reduced $\mathrm{T}^{*}$ values. $\mathrm{T} 2 *$ relaxation times $<10 \mathrm{~ms}$ defines severe cardiac iron overload and has been shown to accurately identify patients at highest risk for developing heart failure and arrthymias. ${ }^{28}$ In fact, cardiac T2* magnetic resonance is superior to serum ferritin and liver iron for risk stratification. Astoundingly, using cardiac $\mathrm{T} 2 *$ to identify the earlier need for intensified iron chelation treatment in high-risk patients has been shown to reduce the high burden of cardiac mortality in myocardial siderosis. Since the introduction of $\mathrm{T} 2 *$ CMR in the United Kingdom in 1999 to identify myocardial 


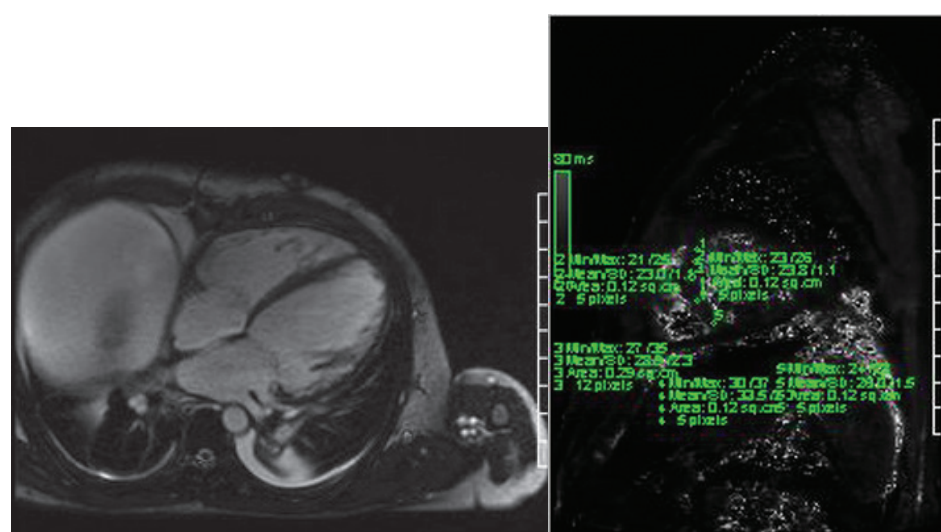

Figure 4. Iron overload cardiomyopathy under treatment. Severe left ventricular (LV) enlargement with moderate global biventricular dysfunction (LV ejection fraction 32\%, right ventricular ejection fraction 36\%) with definite iron overload in the liver (T2* 4 msec) and borderline iron overload in the myocardium (T2* $18 \mathrm{msec}$ ). Late gadolinium enhancement was not performed due to contraindication for gadolinium (renal failure)

siderosis, the appropriate intensification of iron chelation treatment alongside other clinical care improvements has reduced the annualized death rate from iron overload by $71 \%$ in the UK's thalassemia major patients. ${ }^{29}$ Finally, the presence of macroscopic fibrosis, as evidenced by LGE, is uncommon in thalassemia major patients with a broad spectrum of myocardial iron loading. ${ }^{30}$

\section{Other Cardiomyopathies}

Arrhythmogenic right ventricular dysplasia (ARVD) is a genetic disorder of cardiac desmosomes characterized pathologically by fibro-fatty replacement of the RV myocardium. Diffuse disease may later result in LV involvement. Clinical findings include ventricular arrhythmias, sudden cardiac death, and heart failure. Currently, the diagnosis is based on a combination of major and minor diagnostic criteria proposed by the 1994 International Task Force of Cardiomyopathies that include global and regional RV dysfunction and structural alterations, fibro-fatty replacement of the myocardium, ECG changes, and family history ${ }^{31}$ By providing high-resolution 3D multi-planar images, CMR is the best modality for complete RV evaluation and can accurately detect focal thinning, segmental aneurysms, both regional and global RV dilation, and depressed function. Tissue characterization with CMR can further assess for intramyocardial fatty infiltration and fibrosis. Though not a Task Force criterion for the diagnosis of arrhythmogenic right ventricular dysplasia, intramyocardial fat can be suspected with high signal intensity on T1 weighted imaging that is nulled on T2 weighted imaging with fat suppression. ${ }^{32}$ LGE, on the other hand, can assess for myocardial fibro-fatty changes in both the right and left ventricles. The presence of LGE has shown a high degree of correlation with endomyocardial biopsy in ARVD patients and predicts induction of ventricular tachycardia during electrophysiologic testing. ${ }^{33}$

Left ventricular noncompaction (LVNC) is characterized by extensive trabeculations and intratrabecular recesses, occurring more frequently in apical and lateral segments, which give the $\mathrm{LV}$ a "spongy" appearance. Clinical manifestations potentially include cardiac failure, thromboembolism, and malignant arrhythmias. Superior CMR image quality with steady-state free precession cine frames allows the trabeculations to be easily identified (Figure 5). The ratio of 2.3 between the thickness
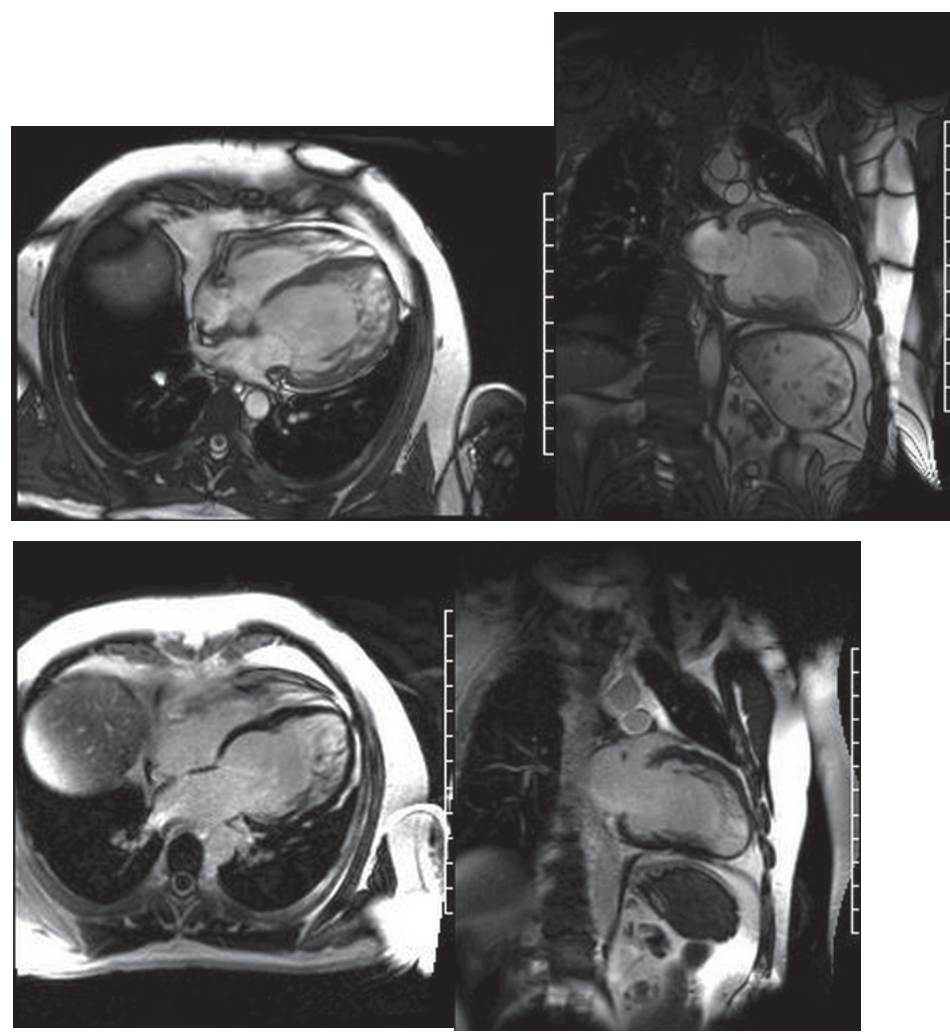

Figure 5. Noncompaction cardiomyopathy. Severely enlarged left ventricle (LV) with LV ejection fraction of $29 \%$. Prominent LV apical trabeculations are seen with a ratio of noncompacted to compacted myocardium of 2.5:1. Late gadolinium enhancement demonstrated contrast uptake within the trabeculations.

of the noncompacted and compacted myocardial layers in diastole distinguishes pathological LVNC from the degrees of noncompaction observed in healthy, dilated, and hypertrophied hearts. ${ }^{34}$ Others have used CMR to quantitate volumetric parameters (LV noncompacted myocardial mass percentage $>25 \%$; $\mathrm{LV}$ noncompacted myocardial mass index $>15 \mathrm{~g} / \mathrm{m}^{2}$ ) to more accurately identify LVNC. ${ }^{35}$ Absence of well-formed papillary muscles is also a helpful clue for diagnosis. Different patterns of LV LGE distribution can be appreciated, and the presence and extent of LV LGE is shown to be independently related to LVEF. ${ }^{36}$ However, the presence of LGE has not reproduced in all the studies, and the role of the absence or presence of LGE in LVNC must be further investigated.

\section{Conclusion}

CMR is a particularly helpful and complementary test to echocardiography in the assessment of nonischemic cardiomyopathies. CMR assets include its excellent unhampered visualization of cardiac structures, quantitative $\mathrm{LV}$ and $\mathrm{RV}$ analysis, and simultaneous flow assessment. Uniquely, it affords the opportunity for noninvasive tissue characterization that readily distinguishes edema, fat, thrombus, and fibrosis. A body of literature is now accumulating delineating the role of LGE in clarifying a diagnosis and in providing further risk stratification independent of other diagnostic variables to further impact patient management. 
Conflict of Interest Disclosure: All authors have completed and submitted the Methodist DeBakey Cardiovascular Journal Conflict of Interest Statement and none were reported

Funding/Support: The authors have no funding disclosures.

Keywords: late gadolinium enhancement, nonischemic cardiomyopathy, $\mathrm{CMR}$, dilated cardiomyopathy, left ventricular noncompaction

\section{References}

1. Maron BJ, Towbin JA, Thiene G, Antzelevitch C, Corrado D, Arnett D, et al. Contemporary definitions and classification of the cardiomyopathies: an American Heart Association Scientific Statement from the Council on Clinical Cardiology, Heart Failure and Transplantation Committee; Quality of Care and Outcomes Research and Functional Genomics and Translational Biology Interdisciplinary Working Groups; and Council on Epidemiology and Prevention. Circulation. 2006 Apr 11;113(14):1807-16.

2. McCrohon JA, Moon JC, Prasad SK, McKenna WJ, Lorenz CH, Coats AJ, et al. Differentiation of heart failure related to dilated cardiomyopathy and coronary artery disease using gadoliniumenhanced cardiovascular magnetic resonance. Circulation. 2003 Jul 8;108(1):54-9.

3. Quarta G, Sado DM, Moon JC. Cardiomyopathies: focus on cardiovascular magnetic resonance. Br J Radiol. 2011 Dec;84 Spec No 3:S296-305

4. Gulati A, Jabbour A, Ismail TF, Guha K, Khwaja J, Raza S, et al Association of fibrosis with mortality and sudden cardiac death in patients with nonischemic dilated cardiomyopathy. JAMA 2013 Mar 6;309(9):896-908.

5. Assomull RG, Prasad SK, Lyne J, Smith G, Burman ED, Khan $\mathrm{M}$, et al. Cardiovascular magnetic resonance, fibrosis, and prognosis in dilated cardiomyopathy. J Am Coll Cardiol. 2006 Nov 21;48(10):1977-85.

6. Wu KC, Weiss RG, Thiemann DR, Kitagawa K, Schmidt A, Dalal $\mathrm{D}$, et al. Late gadolinium enhancement by cardiovascular magnetic resonance heralds an adverse prognosis in nonischemic cardiomyopathy. J Am Coll Cardiol. 2008 Jun 24;51(25):2414-21.

7. Leyva F, Taylor RJ, Foley PW, Umar F, Mulligan LJ, Patel K, et al. Left ventricular midwall fibrosis as a predictor of mortality and morbidity after cardiac resynchronization therapy in patients with nonischemic cardiomyopathy. J Am Coll Cardiol. 2012 Oct 23;60(17):1659-67.

8. Maron MS, Maron BJ, Harrigan C, Buros J, Gibson CM, Olivotto I, et al. Hypertrophic cardiomyopathy phenotype revisited after 50 years with cardiovascular magnetic resonance. J Am Coll Cardiol. 2009 Jul 14;54(3):220-8.

9. Rickers C, Wilke NM, Jerosch-Herold M, Casey SA, Panse P, Panse $\mathrm{N}$, et al. Utility of cardiac magnetic resonance imaging in the diagnosis of hypertrophic cardiomyopathy. Circulation. 2005 Aug 9;112(6):855-61.

10. Choudhury L, Mahrholdt H, Wagner A, Choi KM, Elliott MD, Klocke FJ, et al. Myocardial scarring in asymptomatic or mildly symptomatic patients with hypertrophic cardiomyopathy. J Am Coll Cardiol. 2002 Dec 18;40(12):2156-64

11. Bruder O, Wagner A, Jensen CJ, Schneider S, Ong P, Kispert $\mathrm{EM}$, et al. Myocardial scar visualized by cardiovascular magnetic resonance imaging predicts major adverse events in patients with hypertrophic cardiomyopathy. J Am Coll Cardiol. 2010 Sep 7;56(11):875-87.
12. O'Hanlon R, Grasso A, Roughton M, Moon JC, Clark S, Wage $R$, et al. Prognostic significance of myocardial fibrosis in hypertrophic cardiomyopathy. J Am Coll Cardiol. 2012 Sep 7;56(11):867-74.

13. Rubinshtein R, Glockner JF, Ommen SR, Araoz PA, Ackerman MJ, Sorajja P, et al. Characteristics and clinical significance of late gadolinium enhancement by contrast-enhanced magnetic resonance imaging in patients with hypertrophic cardiomyopathy. Circ Heart Fail. 2010 Jan;3(1):51-8.

14. Green JJ, Berger JS, Kramer CM, Salerno M. Prognostic value of late gadolinium enhancement in clinical outcomes for hypertrophic cardiomyopathy. JACC Cardiovasc Imaging. 2012 Apr;5(4):370-7.

15. Felker GM, Thompson RE, Hare JM, Hruban RH, Clemetson DE, Howard DL, et al. Underlying causes and long-term survival in patients with initially unexplained cardiomyopathy. N Engl J Med. 2000 Apr 13;342(15):1077-84

16. Maceira AM, Joshi J, Prasad SK, Moon JC, Perugini E, Harding I, et al. Cardiovascular magnetic resonance in cardiac amyloidosis. Circulation. 2005 Jan 18;111(2):186-93.

17. Vogelsberg $H$, Mahrholdt $H$, Deluigi CC, Yilmaz A, Kispert EM, Greulich S, et al. Cardiovascular magnetic resonance in clinically suspected cardiac amyloidosis: noninvasive imaging compared to endomyocardial biopsy. J Am Coll Cardiol. 2008 Mar 11;51(10):1022-30

18. Austin BA, Tang WH, Rodriguez ER, Tan C, Flamm SD, Taylor DO, et al. Delayed hyper-enhancement magnetic resonance imaging provides incremental diagnostic and prognostic utility in suspected cardiac amyloidosis. JACC Cardiovasc Imaging. 2009 Dec;2(12):1369-77

19. Syed IS, Glockner JF, Feng D, Araoz PA, Martinez MW, Edwards WD, et al. Role of cardiac magnetic resonance imaging in the detection of cardiac amyloidosis. JACC Cardiovasc Imaging. 2010 Feb;3(2):155-64.

20. Ruberg FL, Appelbaum E, Davidoff R, Ozonoff A, Kissinger $\mathrm{KV}$, Harrigan C, et al. Diagnostic and prognostic utility of cardiovascular magnetic resonance imaging in light-chain cardiac amyloidosis. Am J Cardiol. 2009 Feb 15;103(4):544-9.

21. Maceira AM, Prasad SK, Hawkins PN, Roughton M, Pennell DJ. Cardiovascular magnetic resonance and prognosis in cardiac amyloidosis. J Cardiovasc Magn Reson. 2008 Nov 25;10:54.

22. Migrino RQ, Christenson R, Szabo A, Bright M, Truran S, Hari P. Prognostic implication of late gadolinium enhancement on cardiac MRI in light chain (AL) amyloidosis on long term follow up. BMC Med Phys. 2009 May 5;9:5.

23. Ichinose A, Otani H, Oikawa M, Takase K, Saito H, Shimokawa $\mathrm{H}$, et al. MRI of cardiac sarcoidosis: basal and subepicardial localization of myocardial lesions and their effect on left ventricular function. AJR Am J Roentgenol. 2008 Sep;191(3):862-9.

24. Patel MR, Cawley PJ, Heitner JF, Klem I, Parker MA, Jaroudi WA, et al. Detection of myocardial damage in patients with sarcoidosis. Circulation. 2009 Nov 17;120(20):1969-77.

25. Patel AR, Klein MR, Chandra S, Spencer KT, Decara JM, Lang $\mathrm{RM}$, et al. Myocardial damage in patients with sarcoidosis and preserved left ventricular systolic function: an observational study. Eur J Heart Fail. 2011 Nov;13(11):1231-7. 
26. Watanabe E, Kimura F, Nakajima T, Hiroe M, Kasai Y, Nagata $\mathrm{M}$, et al. Late gadolinium enhancement in cardiac sarcoidosis: characteristic magnetic resonance findings and relationship with left ventricular function. J Thorac Imaging. 2013 Jan;28(1):60-6.

27. Anderson LJ, Holden S, Davis B, Prescott E, Charrier CC, Bunce $\mathrm{NH}$, et al. Cardiovascular T2-star $\left(\mathrm{T}^{*}\right)$ magnetic resonance for the early diagnosis of myocardial iron overload. Eur Heart J. 2001 Dec;22(23):2171-9.

28. Kirk P, Roughton M, Porter JB, Walker JM, Tanner MA, Patel J, et al. Cardiac T2* magnetic resonance for prediction of cardiac complications in thalassemia major. Circulation. 2009 Nov 17;120(20):1961-8.

29. Modell B, Khan M, Darlison M, Westwood MA, Ingram D, Pennell DJ. Improved survival of thalassaemia major in the UK and relation to $\mathrm{T}^{*}{ }^{*}$ cardiovascular magnetic resonance. $J$ Cardiovasc Magn Reson. 2008 Sep 25;10:42.

30. Kirk P, Carpenter JP, Tanner MA, Pennell DJ. Low prevalence of fibrosis in thalassemia major assessed by late gadolinium enhancement cardiovascular magnetic resonance. J Cardiovasc Magn Reson. 2011 Jan 17;13:8

31. Marcus FI, McKenna WJ, Sherrill D, Basso C, Bauce B, Bluemke DA, et al. Diagnosis of arrhythmogenic right ventricular cardiomyopathy/dysplasia: proposed modification of the Task Force Criteria. Eur Heart J. 2010 Apr;31(7):806-14.
32. Jain A, Tandri H, Calkins H, Bluemke DA. Role of cardiovascular magnetic resonance imaging in arrhythmogenic right ventricular dysplasia. J Cardiovasc Magn Reson. 2008 Jun 20;10:32

33. Tandri H, Saranathan M, Rodriguez ER, Martinez C, Bomma C, Nasir K, et al. Noninvasive detection of myocardial fibrosis in arrhythmogenic right ventricular cardiomyopathy using delayedenhancement magnetic resonance imaging. J Am Coll Cardiol. 2005 Jan 4;45(1):98-103

34. Petersen SE, Selvanayagam JB, Wiesmann F, Robson $\mathrm{MD}$, Francis JM, Anderson $\mathrm{RH}$, et al. Left ventricular non-compaction: insights from cardiovascular magnetic resonance imaging. J Am Coll Cardiol. 2005 Jul;46(1):101-5.

35. Grothoff M, Pachowsky M, Hoffmann J, Posch M, Klaassen $S$, Lehmkuhl L, et al. Value of cardiovascular MR in diagnosing left ventricular non-compaction cardiomyopathy and in discriminating between other cardiomyopathies. Eur Radiol. 2012 Dec;22(12):2699-709.

36. Nucifora G, Aquaro GD, Pingitore A, Masci PG, Lombardi M Myocardial fibrosis in isolated left ventricular non-compaction and its relation to disease severity. Eur J Heart Fail. 2011 Feb;13(2):170-6. 